\title{
A comparison of private and public sector intensive care unit infrastructure in South Africa
}

\author{
S Mahomed, MB ChB, MMed; A W Sturm, MD, PhD; P Moodley, MB ChB, PhD \\ School of Laboratory Medicine and Medical Sciences, Nelson R Mandela School of Medicine, College of Health Sciences, University of KwaZulu- \\ Natal, Durban, South Africa
}

Corresponding author: $S$ Mahomed

Background. Intensive care units (ICUs) are designed to care for patients who are often at increased risk of acquiring healthcare-associated infections. The structure of ICUs should be optimally designed to facilitate the care of these critically ill patients, and minimise their risk of infection. National regulations (R158) were developed to govern the building and registration of private hospitals, and until recently equivalent regulations were not available for public hospitals.

Objective. To assess and compare the compliance of ICUs in the private and public sectors with the R158 regulations.

Methods. A cross-sectional study design was used to assess the infrastructure of 25 private sector and 6 public sector ICUs in eThekwini Health District, KwaZulu-Natal Province, South Africa. We used the R158 checklist, which was developed by the KwaZulu-Natal Department of Health Private Licensing Unit and Infection Prevention and Control Unit. The aspects covered in the R158 checklist were categorised into the design, general safety and patient services of the ICUs.

Results. Most of the ICUs in both sectors met the general safety requirements. There were varying levels of compliance with the design criteria. Only $7(28.0 \%)$ and $1(16.7 \%)$ of the private and public ICUs, respectively, had sufficient space around the beds. Twenty-two private ICUs $(88.0 \%)$ and 4 public ICUs $(66.7 \%)$ had isolation rooms, but only some of these isolation rooms (15 private and 2 public) had appropriate mechanical ventilation. None of the ICUs had clinical hand-wash basins in the nurse stations and dirty utility rooms. The majority of the ICUs had the required number of oxygen and electric outlets at the bedside. None of the public ICUs met the light intensity requirement over the bed area.

Conclusions. Adequate spacing in ICUs is an issue in many cases. Interventions need to be put in place to ensure that ICUs meet the relevant design standards. There is an urgent need to revise the R158 regulations to reflect current best practices, particularly with regard to infection control. The same standards should be applied to ICUs in the private and public health sectors to maintain quality of care to patients.

S Afr Med J 2017;107(12):1086-1090. DOI:10.7196/SAMJ.2017.v107i12.12631

Intensive care units (ICUs) are an integral component of health services. These units are designed to accommodate critically ill patients, who are often at increased risk of acquiring healthcareassociated infections. The design requirements of ICUs are based on achieving the optimal physical structure that facilitates the care of these critically ill patients and minimises their risk of acquiring an infection. Furthermore, appropriately designed ICUs can affect patient and staff satisfaction and stress levels. ${ }^{[1]}$ It is therefore imperative that ICUs adhere to infrastructure and design guidelines.

International and national legislation, guidelines and policies have been developed to regulate the layout, ventilation, utility and storage space of ICUs as well as finishes of the flooring, walls, counter tops and ceilings. The aim of these regulations is to minimise the load of pathogens and the risk of transmission in the ICU environment. ${ }^{[2]}$ Adequate spacing of beds and equipment are key factors that facilitate the practice of good infection control in the ICU.

South Africa (SA) has a two-tiered health system, with a wellresourced private sector that services $<20 \%$ of the country's population and an under-resourced public sector that services the rest of the population. ${ }^{[3]}$ ICUs in the public sector are closed units, and patients have to be accepted by the clinician in charge before being admitted. In contrast, ICUs in the private sector are open units and any doctor can admit a patient. ICUs in the private sector therefore cater for patients with varying levels of need in terms of ICU equipment.

As part of SA's political history, policies relating to healthcare differ between the two sectors. Health facility design in the private sector is strictly regulated, but the same regulations do not apply to public health facilities. National regulations (R158) to govern the construction and registration of private hospitals were first gazetted in $1980 .{ }^{[4]}$ These regulations were revised in 1996 but not gazetted. ${ }^{[5]}$ The main considerations of these regulations were cost-effectiveness and patient safety. ${ }^{[5]}$ The 1996 version of the R158 regulations is currently implemented in all provinces except the Western Cape, which implements the R187 regulations that were gazetted provincially in 2001. ${ }^{[6]}$ The R158 regulations consist of three parts: (i) Licensing Control; (ii) Minimum Requirements: Physical Facilities; and (iii) Minimum Operational Standards. The regulations were developed by a multidisciplinary team of health professionals with national representation of the private and public health sectors and cover all discipline-specific areas in a health facility, including ICUs.

In the public sector, guidelines developed by the Infrastructure Unit Support Systems (IUSS) are used for the planning and design of new health facilities. The IUSS is an initiative by the National Department of Health $(\mathrm{NDoH})$ to develop guidelines to standardise the infrastructure of public health facilities. ${ }^{[7]}$ These guidelines are available for public comment before going through the process of being gazetted prior to implementation. The IUSS Health Facility Guide for Adult Critical Care was gazetted in June 2014 and contains infrastructure norms and standards for ICUs. ${ }^{[8]}$ It is stated in these guidelines that they are applicable to public healthcare infrastructure and that they may be used for information or reference in the private sector. ${ }^{[8]}$ The guidelines take into consideration the level of care offered, viz. regional or tertiary, 
when making recommendations on spacing and equipment needs for the ICU. There is currently no system in place in the KwaZulu-Natal Department of Health (KZN DoH) that checks whether facilities comply with the IUSS norms and standards.

\section{Objective}

To assess and compare the compliance of ICUs in the public and private health sectors in KZN with the R158 regulations.

\section{Methods}

\section{Study design and setting}

A cross-sectional study design was used. The study was conducted in eThekwini Health District in KZN. This is the largest district in the province, with the most hospitals with ICUs. In 2014, there were 16 hospitals with 25 ICUs in the private sector in this district. In the public sector, we evaluated 6 ICUs in 3 hospitals.

\section{Data collection}

In the private sector in $\mathrm{KZN}$, as part of the process of application by private health facilities for renewal of their licences, an audit of their compliance with the R158 regulations is conducted annually by a multidisciplinary team using a checklist. This R158 checklist was developed by the KZN DoH Private Licensing Unit and Infection Prevention and Control Unit and is based on the R158 regulations, the National Building Regulations (SABS 0400), and the Occupational Health and Safety Act. Additional elements were added to the checklist that were not stipulated in the R158 regulations, such as the presence of a clinical hand-wash basin in the nurse station.

We used data obtained from the 2013 and 2014 inspections. In the public sector ICUs, the principal investigator and a member of the KZN DoH private licensing team visited each of the ICUs and measured compliance with the R158 regulations using the checklist. A calibrated laser distance measure was used for physical measurements, light emittance was measured using a photometer, and the direction of air flow was determined using a smoke pen.

\section{Ethical considerations}

Permission was obtained from the chief executive officers of the public sector hospitals and from the KZN DoH Health Research Committee. Ethics approval was obtained from the Biomedical Research and Ethics Committee at the University of KwaZulu-Natal (ref. no. BE053/14).

\section{Results}

The aspects covered in the R158 checklist were broadly classified into three areas: (i) design (including spacing); (ii) general safety; and (iii) patient services (Tables 1 and 2 and Fig. 1).

\section{Design of the ICU}

The majority of ICUs in the private and public sectors were exposed to daylight $(21(84.0 \%)$ and $5(83.3 \%)$, respectively). Most of the private sector ICUs had appropriate floor and wall surfaces (23 (92.0\%) and 24 (96.0\%), respectively), compared with 5 (83.3\%) and $3(50.0 \%)$ in the public sector. Only $16(64.0 \%)$ private ICUs and 2 (33.3\%) public ICUs met the requirement for wall length per bed. Even fewer ICUs $(728.0 \%)$ in the private sector and $1(16.7 \%)$ in the public sector) met the minimum requirement for circulation space around the bed. The majority of ICUs (88.0\% private and $83.3 \%$ public) had the appropriate ratio of clinical hand-wash basins to beds. All the ICUs had a nurse station, but none of these nurse stations had a clinical hand-wash basin.
In the private sector, $22(88.0 \%)$ ICUs had isolation rooms of appropriate size. However, only 15 (68.2\%) of these isolation rooms had suitable ventilation. In the public sector, 4 ICUs (66.7\%) had isolation rooms and only $2(50.0 \%)$ of these had suitable ventilation. All the public sector ICUs had appropriately sized dirty utility rooms, compared with only $12(48.0 \%)$ in the private sector.

\section{General safety}

All the ICUs in the private sector had their fire extinguishers and equipment serviced, and $20(80.0 \%)$ had their gas tanks adequately secured. In the public sector, 1 ICU did not have the fire extinguisher and equipment serviced or the electric distribution board cupboard adequately secured, and 2 ICUs did not have the gas tanks adequately secured (Fig. 1).

\section{Patient services}

The majority of ICUs in the private sector $(96.0 \%)$ met the bed service requirements for oxygen, low-pressure medical air and suction (vacuum) points. In the public sector, 3 ICUs (50.0\%) did not have the required number of low-pressure medical air and vacuum services. Light strength was measured in 10 private ICUs, and all met the requirements. In the public sector, only 1 of the ICUs met the light requirement over the bed area (Table 2).

\section{Discussion}

This is the first reported audit and comparison of the infrastructure of ICUs in the private and public health sectors in SA. Public sector ICUs did not comply with many of the R158 requirements. Adequate spacing between beds is an important aspect of patient care and infection control, ${ }^{[1,9]}$ and the majority of ICUs in our setting did not meet this requirement. The IUSS guidelines that currently apply to public hospitals stipulate greater spacing requirements $\left(20\right.$ or $25 \mathrm{~m}^{2}$, depending on the level of care) than the R158 regulations. ${ }^{[8]}$ It is possible that the ICUs in the private sector initially had sufficient spacing, and reduced spacing to accommodate more patients owing to the increased demand for ICU beds.

Daylight in health facilities has been linked to psychological benefits to patients as well as improved patient outcomes. ${ }^{[10]}$ Natural light has also been linked to improved staff morale and physiological health. ${ }^{[11]}$ Although most of the ICUs had daylight provided, it was not sufficient to reach all beds in the ICU and artificial light was required for daily activities in the ward. The use of skylights and design of ICUs to optimise the use of natural light should be considered.

Hand hygiene is the cornerstone of effective infection control. Contrary to the R158 regulations, the Infection Control Assessment Tool that has been adopted by the SA NDoH recommends one hand-wash basin per two beds in an ICU. ${ }^{[12]}$ The IUSS guidelines

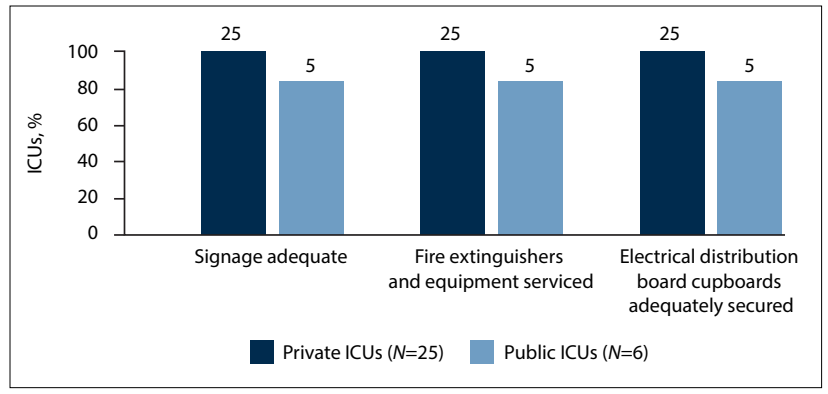

Fig. 1. ICUs complying with general safety criteria as per the R158 regulations. (ICUs = intensive care units. $)$ 
Table 1. ICUs in KwaZulu-Natal complying with design criteria as per the R158 regulations ${ }^{[4,5]}$

\begin{tabular}{|c|c|c|}
\hline Design criteria & $\begin{array}{l}\text { Private }(N=25), \\
n(\%)\end{array}$ & $\begin{array}{l}\text { Public }(N=6), \\
n(\%)\end{array}$ \\
\hline Daylight provided to the ICU & $21(84.0)$ & $5(83.3)$ \\
\hline Floor surfaces smooth, washable, impervious and non-slip & $23(92.0)$ & $5(83.3)$ \\
\hline Wall surfaces smooth, washable and impervious & $24(96.0)$ & $3(50.0)$ \\
\hline Ceilings well maintained & $25(100)$ & $5(83.3)$ \\
\hline Minimum $3.2 \mathrm{~m}$ wall length at head of bed & $16(64.0)$ & $2(33.3)$ \\
\hline Minimum $4 \mathrm{~m}$ clear space between wall at head of bed and foot of bed (including circulation space) & $7(28.0)$ & $1(16.7)$ \\
\hline Patient privacy maintained (screening) & $25(100)$ & $6(100)$ \\
\hline Minimum 1 clinical hand-wash basin per 4 beds & $22(88.0)$ & $5(83.3)$ \\
\hline Nurse station provided & $25(100)$ & $6(100)$ \\
\hline Unobstructed view of all beds or central monitoring & $19(76.0)$ & $6(100)$ \\
\hline Clinical hand-wash basin fitted & 0 & 0 \\
\hline Minimum 1 isolation cubicle provided & $22(88.0)$ & $4(66.7)$ \\
\hline Maximum 1 bed space per cubicle & $22(88.0)$ & $4(66.7)$ \\
\hline Enclosed space with glazed partitions & $22(88.0)$ & $4(66.7)$ \\
\hline Minimum $3.2 \mathrm{~m}$ wall length at head of bed & $22(88.0)$ & $4(66.7)$ \\
\hline Mechanical ventilation with negative pressure installed & $15(60.0)$ & $2(33.3)$ \\
\hline Clinical hand-wash basin fitted & $22^{*}(88.0)$ & $4(66.7)$ \\
\hline Dirty utility room provided & $25(100)$ & $6(100)$ \\
\hline Minimum $5 \mathrm{~m}^{2}$ floor area (sluice only) & $2 / 4(50.0)$ & \\
\hline Minimum $7 \mathrm{~m}^{2}$ floor area (shared cleaner's room or storage of soiled linen and waste) & $1 / 4(25.0)$ & \\
\hline Minimum $9 \mathrm{~m}^{2}$ floor area (shared cleaner's room and storage of soiled linen and waste) & $9 / 17(52.9)$ & $6(100)$ \\
\hline Hand-wash basin fitted ${ }^{\dagger}$ & $16(64.0)$ & $4(66.7)$ \\
\hline Sluice sink fitted & $23(92.0)$ & $6(100)$ \\
\hline Wall-mounted bed pan and urinal rack in place & $25(100)$ & $6(100)$ \\
\hline \multicolumn{3}{|l|}{ Suitable storage space provided } \\
\hline Equipment & $18(72.0)$ & $5(83.3)$ \\
\hline Supplies & $22(88.0)$ & $6(100)$ \\
\hline Visitors' waiting area available & $21(84.0)$ & $5(83.3)$ \\
\hline Staff toilet provided & $25(100)$ & $6(100)$ \\
\hline Staff rest room provided & $25(100)$ & $6(100)$ \\
\hline Kitchen or kitchenette facilities provided & $18(72.0)$ & $5(83.3)$ \\
\hline Clinical hand-wash basin fitted & 0 & 0 \\
\hline
\end{tabular}

Table 2. ICUs in KwaZulu-Natal complying with patient services criteria as per the R158 regulations ${ }^{[4,5]}$

\begin{tabular}{|c|c|c|}
\hline Patient services criteria & $\begin{array}{l}\text { Private }(N=25), \\
n(\%)\end{array}$ & $\begin{array}{l}\text { Public (N=6), } \\
n(\%)\end{array}$ \\
\hline \multicolumn{3}{|l|}{ Bed services } \\
\hline Three oxygen outlets per 2 beds & $24(96.0)$ & $5(83.3)$ \\
\hline Three low-pressure medical air outlets per 2 beds & $24(96.0)$ & $3(50.0)$ \\
\hline Three vacuum (suction points) per 2 beds & $24(96.0)$ & $3(50.0)$ \\
\hline Eight 15 amp electric switched socket outlets per bed & $21(84.0)$ & $4(66.7)$ \\
\hline Ten 15 amp electric switched socket outlets per bed (cardiothoracic, thoracic, neuro ICU) & $4^{*}$ & $2^{\dagger}$ \\
\hline \multicolumn{3}{|l|}{ Lighting } \\
\hline 400 lux over whole bed area for observation & $10^{\ddagger}$ & 0 \\
\hline 10000 lux for local examination luminaire & $10^{\ddagger}$ & $1(16.7)$ \\
\hline $\begin{array}{l}\text { ICU = intensive care unit. } \\
{ }^{*} \text { specialisised private ICUs. } \\
\text { 2 specialised public ICU. } \\
\text { thight }\end{array}$ & & \\
\hline
\end{tabular}

recommend that each bed space in an ICU should have a clinical hand-wash basin; ${ }^{[8]}$ this was achieved only in the private sector ICUs with partitioned bed spaces. Fulfilling this requirement in all ICUs would be a challenge in both the public and the private sector, as it would require extensive renovations. Designing ICUs with individual rooms is costly and is unlikely to be implemented in 
the public sector owing to resource constraints. The R158 checklist and IUSS guidelines stipulate that the nursing station should have a clinical hand-wash basin, and none of the ICUs complied with this requirement. Availability and visibility of hand-wash basins facilitates adherence to hand hygiene, ${ }^{[13-15]}$ and distance between patient zone and hand-wash basin has also shown to be inversely associated with adherence to hand hygiene. ${ }^{[14]}$

Neither the IUSS guidelines nor the R158 regulations stipulate that a clinical hand-wash basin be placed in the dirty utility room and staff rest room. However, a clinical hand-wash basin in these rooms is essential for maintaining good infection control standards, and is recommended in international guidelines. ${ }^{[1,9]}$ Shortage of sinks and inconveniently located sinks have been reported as barriers to hand hygiene by healthcare workers. ${ }^{[16]}$ Clinical hand-wash basins have been designed to minimise the risk of recontamination after handwashing, and it is therefore important that the dirty utility room and staff rest room have clinical handwash basins. The link between suboptimal hand hygiene and the risk of healthcare-associated infections has been well established, ${ }^{[13]}$ so addressing these barriers would be important in reducing the risk of healthcare-associated infections in the ICU. The KZN DoH private licensing team made recommendations to health facilities to provide clinical hand-wash basins in the aforementioned rooms and the nurse station, and this was followed up on during subsequent accreditation visits by the team.

A central nurse station with visibility of all patients in the ICU is recommended in both the R158 regulations and the IUSS guidelines. While this requirement is also noted internationally, the central nurse station is not meant to substitute for the nurse's bedside activity. ${ }^{[9]}$ Single-bed rooms with decentralised nursing stations are better than multiple-bedded units in terms of infection control, and are also less disruptive to the nursing care of patients. ${ }^{[1]}$ Since ICUs have a 1:1 nurse/ patient ratio, we advocate for nurse stations to be located at the patient bedside, with a conveniently located administrative station in the ICU.

The R158 regulations stipulate the need for an isolation cubicle but do not refer to the quantity in relation to patient beds, whereas the IUSS guidelines recommend one isolation room per six-bed ICU. ${ }^{[8]}$ The recommended number of isolation beds differs between organisations. European guidelines recommend one to two isolation rooms per $10 \mathrm{ICU}$ beds, ${ }^{[9]}$ whereas the Facility Guidelines Institute and the Society for Critical Care Medicine in the USA recommend that the number of isolation rooms should be based on the disease burden in the community served by the health facility. ${ }^{[1]}$ In lowresource settings, it has been recommended that the number of isolation rooms should be at least $10 \%$ of the total number of ICU beds. ${ }^{[17]}$ Appropriate mechanical ventilation in an isolation room is of paramount importance in reducing the risk of transmission of infection. ${ }^{[2]}$ In our setting, the majority of isolation rooms did not have suitable mechanical ventilation. The eThekwini Health District has a high burden of patients with immunocompromising diseases such as HIV infection and diabetes mellitus, as well as a high burden of drug-resistant tuberculosis. ${ }^{[18,19]}$ This combination of epidemics, together with an insufficient number of isolation rooms and isolation rooms without appropriate ventilation, increases the risk of transmission of infections in a health facility.

The IUSS light intensity requirement over the bed area $(300 \mathrm{lux})^{[20]}$ is lower than that stipulated in the R158 regulations (400 lux) ${ }^{[5]}$ and none of the ICUs in the public sector met this IUSS requirement. In the private sector, light intensity was not measured in more than $50 \%$ of the ICUs owing to unavailability of a photometer. Insufficient light intensity in the ICU has been reported in other settings, and its effect on patients' circadian rhythms is unclear ${ }^{[2]]}$ and requires further investigation.

The R158 regulations make reference to storage of pharmaceutical products, but do not refer to the management of medications in the ICU. Although management of medications may not be directly related to infrastructure, their access and control must adhere to local policies and guidelines, as mentioned in the IUSS guidelines. ${ }^{[8]}$ The Medicines and Related Substances Act ${ }^{[22]}$ refers to the safety, security, purchasing, storage and dispensing of medicines in a hospital, but there are no specific requirements as to how this should be done. The Good Pharmacy Practice guidelines ${ }^{[23]}$ do not specifically refer to medication storage facilities in a hospital ward, and in general recommend locked storage space for schedule 6 medications. ${ }^{[23]}$ We advocate that an ICU should have a fixed lockable cupboard with restricted access for the management of schedule 5 and 6 medications, and that this should be explicitly stated in the R158 and IUSS guidelines.

\section{Study limitations}

This research is a comprehensive assessment of various aspects of the design and environmental factors affecting ICUs. However, there were some limitations. There are far fewer ICUs in the public sector than in the private sector, and only 6 of the 10 public sector ICUs were included. We did not include highly specialised units such as the transplant ICU, very small units ( $\leq 4$ beds), and ICUs that were not being used at the time of the research. The checklist used was based on an old regulation, and the new aspects of the checklist were contested by some private sector health facilities, as the 1996 version of the R158 did not go through the correct legal processes before being implemented. Despite the recommendation that the R158 regulations should be reviewed annually by a committee with private and public sector representation, ${ }^{[5]}$ this has not been done. Except for the ICUs at the central hospital in eThekwini Health District, the remaining ICUs are in hospitals with ageing infrastructure and in dire need of refurbishment. In contrast, hospitals in the private sector are newer and are renovated and refurbished more frequently. It was therefore expected that the public sector ICUs would be less likely than the private sector ones to meet many of the R158 or IUSS criteria.

\section{Conclusions}

ICUs in both the private and the public sectors do not meet all the criteria of the R158 regulations or the IUSS guidelines. The R158 regulations are outdated and do not reflect current best practices, particularly with regard to infection control. A comprehensive assessment of all ICUs in the district is required to determine priority areas for improving critical care services. The level of care provided in ICUs in the private sector is not prescribed by any policy or regulation, and all ICUs in the private sector should therefore also be subject to meeting the IUSS criteria for tertiary care ICUs. The standards applied to the building of health facilities and the standard of patient care should not differ between the public and private sectors, and ideally the same regulations and guidelines should be applicable to both.

Acknowledgements. We would like to thank the KZN DoH Private Licensing Team and Infection Prevention and Control Unit for their assistance with access to data and data collection.

Author contributions. SM researched the literature, conceived the study, developed the protocol, obtained ethical approval, analysed the data and 
wrote the first draft of the manuscript; AWS and PM contributed to the concept and design of the research, analysis and interpretation of the data, and reviewed the article for important intellectual content; and all the authors reviewed the manuscript and approved the final version of the manuscript.

Funding. This publication was made possible by grant no. 5R24TW008863 from the Office of the Global AIDS Coordinator and the US Department of Health and Human Services, National Institutes of Health (NIH OAR and NIH OWAR). Its contents are solely the responsibility of the authors and do not necessarily represent the official views of the government.

Conflicts of interest. None.

1. Rashid M. Two decades (1993 - 2012) of adult intensive care unit design: A comparative study of the physical design features of the best practice examples. Crit Care Nurs Q 2014;37(1):3-32. https://doi. org/10.1097/CNQ.0000000000000002

2. O'Connell $\mathrm{NH}$, Humphreys $\mathrm{H}$. Intensive care unit design and environmental factors in the acquisition of infection. J Hosp Infect 2000;45(4):255-262. https://doi.org/10.1053/hinin.2000.0768

3. Padarath AKJ, Mackie E, Casciola J. South African Health Review. Durban: Health Systems Trust, 2016.

4. National Department of Health, South Africa. Regulations Governing Private Hospitals and Unattached Operating Theatre Units (1980). http://www.kznhealth.gov.za/regulations/pvthosp.pdf (accessed 7 ovember 2017).

5. National Department of Health, South Africa. R158 Regulations Governing Patient Care Facilities. Pretoria: National Department of Health, 1996.

6. Western Cape Department of Health. Regulations Governing Private Health Establishments: R187. Cape Town: Western Cape Department of Health, 2001.

7. Infrastructure Unit Support Systems. IUSS Online Improving South Africa's Healthcare Infrastructure. Council for Scientific and Industrial Research, 2017. http://www.iussonline.co.za/index.php/about (accessed 10 May 2015).

8. Infrastructure Unit Support Systems Norms and Standards Task Group A: 02 2014. Adult Critical Care. No. 37790 R512. Pretoria: National Department of Health, South Africa, 2014.
9. Valentin A, Ferdinande P. Recommendations on basic requirements for intensive care units: Structural and organizational aspects. Intensive Care Med 2011;37(10):1575-1587. https://doi.org/10.1007/s00134and organizati-2300-7

10. Van den Berg AE. Health Impacts of Healing Environments: A Review of Evidence for Benefits of Nature Daylight, Fresh Air, and Quiet in Healthcare Settings. Groningen: University Hospital Groningen, 2005. Zadeh RS, Shepley MM, Williams G, Chung SS. The impact of windows and daylight on acute-care Zadeh RS, Shepley MM, Williams G, Chung SS. The impact of windows and daylight on acute-care
nurses' physiological, psychological, and behavioral health. HERD 2014;7(4):35-61. https://doi. nurses' physiological, psychologica,
org/10.1177/193758671400700405

12. National Department of Health, South Africa. Infection Control Assessment Tool. Pretoria: NDoH, 2014 3. Boyce JM, Pittet D. Guideline for hand hygiene in health-care settings: Recommendations of the Healthcare Infection Control Practices Advisory Committee and the HICPAC/SHEA/APIC/IDSA Hand Hygiene Task Force. Infect Control Hosp Epidemiol 2002;23(12 Suppl):S3-S40. https://doi. org $/ 10.1086 / 503164$

14. Deyneko A, Cordeiro F, Berlin L, Ben-David D, Perna S, Longtin Y. Impact of sink location on hand hygiene compliance after care of patients with Clostridium difficile infection: A cross-sectional study. BMC Infect Dis 2016;16:203. https:// doi.org/10.1186/s12879-016-1535-X

15. Cloutman-Green E, Kalaycioglu O, Wojani H, et al. The important role of sink location in handwashing compliance and microbial sink contamination. Am J Infect Control 2014;42(5):554-555. https://doi. compliance and microbial siak
org/10.1016/j.ajic.2013.12.020

16. Pittet D. Improving compliance with hand hygiene in hospitals. Infect Control Hosp Epidemiol

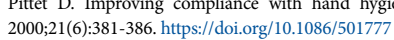

17. 2000;21(6):381-386. https://doi.org/10.1086/501777

18. Sahadew N, Brown S. Distribution, incidence, prevalence and default of patients with diabetes mellitus accessing public healthcare in the 11 districts of KwaZulu-Natal, South Africa. S Afr Med 2016;106(4):389-393. https://doi.org/10.7196/SAMJ.2016.v106i4.10143

19. Massyn N, Peer N, English R, Padarath A, Barron P, Day C. District Health Barometer 2015/16. Durban: Health Systems Trust, 2016.

20. Infrastructure Unit Support Systems. Building Engineering Services. Pretoria: National Department of Health, South Africa, 2016

21. Durrington HJ, Clark R, Greer R, et al. 'In a dark place, we find ourselves': Light intensity in critical care units. Intensive Care Med Exp 2017;5:9. https://doi.org/10.1186\%2Fs40635-017-0122-9

22. South Africa. Medicines and Related Substances Act No. 101 of 1965

23. South African Pharmacy Council. Good Pharmacy Practice in South Africa. 4th ed. Pretoria: SAPC, 2010. 